\title{
Hydroxychloroquine and Remdesivir in COVID-19: A critical analysis of recent events
}

\author{
AMIT DANG, VALLISH BN, SUMIT DANG
}

\begin{abstract}
The world is going through an unprecedented medical emergency with no effective remedy for the SARS-CoV2 virus causing Covid-19. Two drugs used for other indications in the past, hydroxychloroquine (HCQ) and remdesivir (RDV), are sought to be repurposed to treat Covid-19. Both these drugs have received emergency use authorisation by the US Food and Drug Administration. In this review, we critically analyse the identification of and subsequent events concerning these two drugs as potential treatment options for Covid-19, and conclude by raising some ethical issues that require serious thought from the global scientific community concerned with using these two drugs against Covid-19.
\end{abstract}

Key Words: Covid-19, hydroxychloroquine, remdesivir, USFDA, emergency use authorisation

\section{Introduction}

As on June 10, 2020, there are 7.09 million confirmed cases of Covid-19, and 406,461 deaths, at a mortality rate of $6.88 \%$. With 1.95 million confirmed cases and 110,770 deaths, the USA is the worst sufferer, in terms of numbers, due to the disease (1). Given the sudden and severe nature of the disease and its high rate of contagion, and the costs and time involved in the development and marketing of a new, safe and efficacious drug, researchers around the world are looking to repurpose known drugs to treat Covid-19.

Since SARS-CoV-2, the causative agent of Covid-19, has a close genetic resemblance with the severe acute respiratory syndrome (SARS-CoV) and the Middle East respiratory syndrome (MERS CoV) (2), drugs used to treat SARS and MERS were revisited to explore the extent of their activity against SARS-CoV-2. Accordingly, a study from China published on February 4, found that chloroquine (CQ) and remdesivir (RDV)

Authors: Amit Dang (corresponding author - amit.d@marksmanhealthcare. com), Founder and CEO, MarksMan Healthcare Communications and KYT Adhere, H No 9-1-67, Plot 67, Behind Q City, Hyderabad, INDIA; Vallish BN (vallish.bn@marksmanhealthcare.com), Senior Consultant, Medical Writing and Biostatistics, MarksMan Healthcare Communications, H No 9-1-67, Plot 67, Behind Q City, Hyderabad, INDIA; Sumit Dang (sumitdang@uky.edu), Department of Paediatrics, University of Kentucky, USA

To cite: Dang A, Vallish BN, Dang S. Hydroxychloroquine and Remdesivir in COVID-19: A critical analysis of recent events. Indian J Med Ethics. 2020 JulSep. 5(3) NS: 202-7.DOI: 10.20529/JMME.2020.068.

Published online on June 18,2020

Manuscript Editor:Vijayaprasad Gopichandran

() Indian Journal of Medical Ethics 2020 effectively blocked the SARS-CoV-2 infection of Vero E6 cells with high selectivity (2).

\section{Chloroquine and hydroxychloroquine}

CQ has been used for over 70 years for treating conditions like CQ-sensitive malaria, extraintestinal amoebiasis, systemic lupus erythematosus (SLE), and rheumatoid arthritis (RA) $(3,4)$. The side effects of CQ are relatively few when taken in prescribed doses. At higher doses, chloroquine is associated with ophthalmologic reactions including retinal toxicity, reduced visual acuity, visual loss, and diplopia, due to the selective binding of CQ to retinal melanin $(5,6)$. A 2018 systematic review reported no serious cardiac adverse effects including arrhythmias with CQ (7). Further, a 2014 study involving 317 SLE patients suggested that CQ additionally plays a protective role against an unexpectedly high rate of cardiac arrhythmias and conduction disturbances (8).

$H C Q$, a less toxic derivative of $C Q$, has been used for a long time for treating conditions such as RA, juvenile idiopathic arthritis, and Sjogren's syndrome (9). The toxicity profile of HCQ is largely similar to that of CQ (9). Cardiotoxicity, rarely reported after prolonged treatment with $\mathrm{HCQ}$, is typically manifested as cardiomyopathy or conduction abnormalities (10). Also, HCQ has been documented to be safe during pregnancy (11). Due to considerations of lower toxicity and cost, $\mathrm{HCQ}$ was endorsed for usage in Covid-19 therapy (12). A lower dose HCQ for prophylaxis of Covid-19 was also proposed (13).

The potential of HCQ in Covid-19 was quickly publicised in the media. Anticipating that the indiscriminate use of the inexpensive HCQ may lead to drug shortages, instil a false sense of security, and potentially cause widespread HCQ toxicity; and considering the lack of objective evidence of the effectiveness of HCQ against SARS-CoV-2, an emphatic demand for well-designed clinical trials evaluating the same was repeatedly made (14-16). Simultaneously, clinical trials exploring the efficacy and safety of HCQ to treat and prevent Covid-19 were initiated. Though an early clinical trial from France strongly suggested that HCQ was associated with viral load reduction/disappearance in Covid-19 patients (17), concerns were raised about the study methodology (18). An observational study published in May 2020 found that $\mathrm{HCQ}$ administration was not associated with a statistically significant increase or decrease in the composite end point of intubation or death. However, HCQ-treated patients in this study had been more severely ill than those who did not receive HCQ treatment (19). A retrospective analysis of Covid-19 patients from New York treated with HCQ alone or with azithromycin, reported no significant mortality benefit of $\mathrm{HCQ}$ when compared to patients not administered either 
drug. However, even in this study, the patients treated with HCQ were more severely ill at baseline (20). It is interesting to note that despite HCQ being given to more severely ill individuals, at the end of the study the mortality rate of these patients was similar to that of the less sick individuals who had not received HCQ. This point was not highlighted in either of the studies. Another retrospective analysis published in May 2020 reported that treatment of Covid-19 patients with a combination of HCQ and azithromycin resulted in a good clinical outcome and virological cure within 10 days of treatment in $91.7 \%$ (973/1061) of the patients. QTC prolongation was observed in 9/1061 patients, and none of the 8 deaths in the study was attributed to cardiac toxicity. Only $2.3 \%$ of patients had adverse events, which were mild, including gastrointestinal (Gl) disturbances, skin symptoms, headache, insomnia and transient blurred vision (21). On March 18 2020, the WHO also started the Solidarity trial to compare four different treatment options for Covid-19 management, including RDV, HCQ, lopinavir/ritonavir, and lopinavir/ritonavir/interferon-beta-1a. (22).

On February 18, 2020, the National Health Commission of China included CQ in the revised 6th version of its guidelines for diagnosis and treatment of Covid-19 (23). On March 21 2020, the Indian Council of Medical Research (ICMR) issued guidelines approving the prophylactic use of HCQ among asymptomatic healthcare workers involved in Covid-19 management, and asymptomatic household contacts of laboratory-confirmed cases of Covid-19 (24). The prophylactic use of HCQ has now been expanded in May 2020, to include all asymptomatic healthcare workers irrespective of being involved in Covid-19 management, and all asymptomatic nonhealthcare personnel involved in Covid-19 containment efforts. The revised guidelines were based on review of top-line data from multiple clinical studies conducted in India's hospitals involved in Covid-19 management (25).

In the USA, following the President's endorsement of HCQ (26), the USFDA on March 28, 2020 issued an emergency use authorisation (EUA) of HCQ to treat "patients who are hospitalized with Covid-19", and HCQ was authorised for treating patients "for whom a clinical trial is not available, or participation is not feasible" (27). However, by this time, a large number of clinical trials for Covid-19 had already started, and the inclusion of these conditions in the EUA meant that those patients already in clinical trials could not be administered HCQ for treating Covid-19, thereby lowering the potential number of recipients of the drug. Furthermore, the EUA also emphasised that there were "limited in-vitro and anecdotal clinical data in case series" regarding the efficacy of HCQ in Covid-19 (27). However, it is interesting to observe that a letter published twelve days earlier had reported that chloroquine had acceptable efficacy and safety in treating Covid-19, as seen in several clinical trials involving over 100 patients conducted across China. This was the basis for including CQ in the Chinese Covid-19 guidelines (28). Also, while HCQ was recommended for Covid-19 prophylaxis in India; in the USA, it was intended to treat patients with confirmed Covid-19.
After the ICMR guidelines and USFDA EUA permitted the use of HCQ in Covid-19, varied opinions were expressed within the scientific community $(29,30)$. Some researchers raised concerns that with increased use of $\mathrm{HCQ}$, there may be a corresponding increase in rates of rare but serious cardiac adverse effects including QTc prolongation (31); contrasting reports about the absence of such cardiac adverse effects were also published (32). Others were concerned that overenthusiastic use of HCQ would lead to HCQ shortages, and this may adversely impact rheumatology patients who were prescribed HCQ for other conditions (33). Criticisms were also directed towards the quality of clinical trial evidence that supported the use of HCQ in Covid-19 (34).

The dosage recommendation for HCQ has also varied widely: the prophylactic regimen recommended by the ICMR advised that $400 \mathrm{mg}$ of HCQ be given twice on day 1, then $400 \mathrm{mg}$ once weekly for seven weeks (for healthcare workers) or three weeks (for asymptomatic contacts) (24). Chinese experts recommended a dosage of $\mathrm{CQ}$ at $500 \mathrm{mg}$ twice daily for 10 days (35). The USFDA-approved therapeutic dose for HCQ is $800 \mathrm{mg}$ on day 1, followed by $400 \mathrm{mg}$ daily for 4-7 days (36).

\section{Remdesivir}

The second drug considered promising for repurposing against Covid-19, after being identified by Wang et al (2), was remdesivir (RDV). RDV is a broad-spectrum antiviral agent originally synthesised and developed in 2013-14 to treat infections by hepatitis $C$ virus and respiratory syncytial virus. During the 2014 Ebola virus outbreak, RDV demonstrated activity against Ebola virus in cell lines and in Rhesus monkeys infected with the virus (37). A subsequent clinical trial concluded that administration of monoclonal antibodies (REGN-EB3 and mAB114) was associated with higher survival rates than RDV against Ebola (38). The clinical efficacy of RDV was not conclusively demonstrated in the treatment of Ebola and Marburg infections (39).

RDV has documented activity against SARS-CoV and MERS-CoV through in-vitro and animal studies (40-42). Being a relatively recent drug, the clinical safety data of RDV is not yet adequate. Its documented adverse effects are gastrointestinal symptoms, elevated transaminases, and longer clotting times, and possible non-significant drug interactions following co-administration of other drugs which induce the CYP enzymes (43). As with to $\mathrm{HCQ}$, many clinical trials are being conducted to explore the efficacy and safety of RDV in Covid-19. Grein et al published the results of RDV administered open-label on a compassionateuse basis on April 10, 2020, and a clinical improvement was observed in 36/53(67.9\%) patients (44). This paper documented that RDV administration was associated with adverse events in 32/53(60.3\%) patients, which included liver enzyme elevation and renal impairment in 12 and 4 patients respectively. Four patients discontinued RDV treatment prematurely. Despite this, the authors concluded that there were no new safety signals of concern (44). In late April, a randomised controlled trial, wherein RDV was administered 
to 237 Chinese patients with laboratory-confirmed SARSCoV-2 infection, observed that RDV did not show statistically significant clinical improvement compared with placebo, and RDV was stopped early in 18 patients due to adverse events. Further, RDV was not associated with significant mortality benefit after 28 days of hospitalisation, and virological clearance was observed in only $37 / 236(19 \%)$ patients. This trial, in which the drug did not seem to have significant clinical benefits, was terminated prematurely, and the reason given by the authors was that there was a difficulty in recruiting Covid-19 patients as the pandemic had been brought under control in China (45). This led to the opinion that while RDV "might be helpful, it is not a wonder-drug" (46).

On May 1, 2020, the USFDA granted an EUA for RDV to treat patients with "suspected or laboratory confirmed" severe Covid-19, based on review of top-line data from two trials (NCT04280705, NCT04292899) (47). Preliminary study data from the first study (NCT04280705), which was sponsored by the National Institute of Allergy and Infectious Diseases (NIAID), suggested that compared to placebo, RDV shortens time to recovery by $31 \%$ (from 15 days to 11 days) significantly; however, its mortality benefit is not significant (48). The RDV's EUA also placed no restrictions regarding the patients' participation in clinical trials for RDV treatment. Concerns about removing "death" from the list of primary outcomes of the NIAID-funded trial drew criticisms on the internet (49). Further, it is interesting to note that the use of RDV outside of approved clinical trials is not recommended in Canada (50).

\section{Recent developments}

There have been rapid developments pertaining to the use of HCQ vs RDV in treating Covid-19:

On May 26, 2020, in response to a Lancet paper published four days earlier that suggested that all drug regimens involving $\mathrm{HCQ}, \mathrm{CQ}$, and macrolides resulted in an increased risk of inhospital mortality and ventricular arrhythmias, the WHO issued a notification to temporarily halt the HCQ arm of the "Solidarity" trial (51). However, following widespread criticism of the Lancet paper, especially regarding non-adherence to standard practices, non-disclosure of data, not conforming to ethical review, and non-disclosure of location of the study (52), the Lancet retracted the paper (53). The ICMR also wrote to WHO highlighting the gross difference in the higher and riskier dose of HCQ used by international studies, and the lower dose advocated by ICMR in India. While the total maximum dose as per the ICMR guidelines amounts to $2400 \mathrm{mg}$ over 5 days, the $\mathrm{HCQ}$ dose in the Solidarity trial is as high as $9600 \mathrm{mg}$ in 11 days (54). Interestingly, the RECOVERY trial, started in the UK with similar designs as the Solidarity trial, explicitly instructed the principal investigators to continue recruitment of patients into the HCQ arm, even after the HCQ arm was temporarily halted in the Solidarity trial following the Lancet study's publication (55).

Meanwhile, after EUA was granted for RDV use to treat Covid-19 patients in the USA, manufacture of RDV was started in India as on May 12, 2020, to enhance drug supply to countries where RDV is approved for treatment (56). On May 22, 2020, the NIAID trial was published in the New England Journal of Medicine, and though RDV showed a shorter recovery time in hospitalised Covid-19 patients, a significant mortality benefit was conspicuously absent with RDV; this aspect of lack of mortality benefit was not sufficiently highlighted by the authors (57). On June 1, 2020, top-line results of phase- 3 trials using RDV in patients with moderate Covid-19 reported that a 5-day-treatment course of RDV was associated with significant clinical improvement (up to 65\%) on day 11); however, a 10-day treatment course of RDV did not result in any significant improvement. There was again no mention of absence of mortality benefit with RDV (58).

\section{RDV vs HCQ: Ethical concerns}

Analysis of various studies available at present does not prove a clear and conclusive efficacy benefit for either RDV or HCQ in clinical trials. It appears that a subtle push is being given to RDV, the safety of which is not adequately established; while HCQ is being subtly snubbed, despite both drugs having similar efficacy patterns. This appears to be in contravention of the basic ethical principles of beneficence, non-maleficence, autonomy, and justice. Scrutiny of the EUAs and other recent events surrounding these two drugs yields some disquieting observations.

\section{Safety}

The safety profile of HCQ is well-known since it has been in use for various other conditions as well. On the other hand, RDV has not been in long-term use for any other condition, and lacks a clear safety profile. In the compassionate use study (44), even though Grein et al concluded that there are no safety concerns, the fact remains that significant adverse effects were observed among RDV recipients, with some of them discontinuing the treatment. In our opinion, anticipatory management of known safety risks is better than managing the adverse effects of a drug with an unknown safety profile. Surprisingly, the EUAs of both HCQ and RDV do not contain any significant information about the safety aspect of the drugs. On the other hand, there has been an interesting surge in reports of HCQ-induced QTC prolongation after the issuance of the HCQ EUA. Further, the number of patients who have received HCQ for Covid-19 in trials reported so far is larger than the number of patients who have received RDV for the same indication; thus, the safety profile of RDV for Covid-19 has not been adequately studied in a sufficiently large number of patients.

\section{Cost}

As per estimates of the Institute for Clinical and Economic Review (ICER), a 10-day course of RDV could have a price of USD 4500, as compared to a production cost of USD 10 (59). In contrast, HCQ is inexpensive by a wide margin. Favouring the expensive RDV over an inexpensive HCQ in treating Covid-19 might have significant implications in countries like India where a large proportion of medical expenditure is spent outof-pocket. 


\section{Efficacy}

Both HCQ and RDV were shown to inhibit the in-vitro growth of SARS-CoV-2. The inconsistent, albeit non-specific, antiviral activity of HCQ has been documented in the past as well. A recent study has indicated that $\mathrm{HCQ}$ co-administered with azithromycin provides virological cure and low mortality with no cardiac toxicity (21). However, the efficacy of RDV in Ebola virus was not fully established (39). Also, the NIAID trial reports that RDV shortens time to recovery by a median of four days, but without any significant mortality benefit (57). Finally, RDVinduced virological cure rates were significantly low in the Wang et al study published in the Lancet (45).

\section{Conditions of use}

The EUA for HCQ restricts its use to patients with "known" Covid-19, who are "not part of clinical trials"; whereas the EUA for RDV does not have either of these restrictions: RDV may be administered to patients with "suspected" or confirmed COVID-19, not necessarily restricted to those in clinical trials. With fewer restrictions on drug administration, it would be legally easier for a US-based clinician treating Covid-19 to administer RDV than HCQ.

\section{Prevention versus treatment}

Though it was suggested that HCQ can be used for Covid-19 prophylaxis in low and safe doses, the USFDA recommended higher and toxic doses intended for therapy and not prevention (36). With higher doses, toxic effects are also observed more often, as reported by an interim analysis of a randomised trial (60), and this is in line with the principles of toxicology. Interestingly, the USFDA's communication of April 24,2020 , cautioned against the use of HCQ outside of hospital settings or a clinical trial, thereby preventing the possible prophylactic use of HCQ for at-risk people (61).

\section{Focus of scrutiny}

Criticism of HCQ has been focused on safety (increased risk of adverse events and arrhythmias), followed by efficacy (lack of clinical or mortality benefit). However, there has been no acknowledgement of the high dose of $\mathrm{HCQ}$ given when compared to the lower dose recommended by the ICMR. On the other hand, the lack of mortality benefit with RDV is being downplayed, and attempts to highlight a lack of new safety risks, despite observations to the contrary, are repeatedly made. It appears as if $\mathrm{HCQ}$ is being more closely scrutinised when compared to the lighter treatment given to RDV. While the widespread (mostly unsupervised) use of HCQ for other indications may have contributed to these unequal levels of scrutiny, confounders such as political affiliation, profiteering, and other conflicts of interest cannot be ruled out at this stage, with the available evidence and information.

\section{Conclusions and the way ahead}

In times of crises, such as the present, it is essential for all stakeholders to act in the most ethical manner, and to give humanity precedence over everything else, including political affiliation, profit making, personal views, and any other conflict of interest. The ethical issues raised by us through scrutiny of the events surrounding HCQ and RDV need serious consideration by all concerned. It might be possible that these concerns and doubts have already arisen among the medical fraternity. A head-to-head comparison of HCQ vs RDV has the potential to clear doubts on the efficacy and safety of these two drugs. At the time of writing, six such trials have been registered in the clinicaltrials.gov database and four of these studies have started recruiting patients; this is in addition to the Solidarity trial and RECOVERY trials. Regulators should base their decisions for use of treatment options on such impartial and ethical comparisons and set an exemplary standard for all to follow.

\section{Acknowledgements: None}

Conflicts of interest and funding: The authors declare no conflicts of interest with respect to HCQ or RDV as part of their clinical trials, data science, or healthcare communications work. The work was self-funded.

Ethics approval: This is a narrative literature review, and since there is no direct data collection from patients, ethics committee approval is not applicable.

\section{References}

1. World Health Organization. WHO Coronavirus disease (COVID-19) Dashboard. Updated 2020 May 13[cited 2020 Jun 10]. Available from: https://covid19.who.int/

2. Wang $M$, Cao R, Zhang L, Yang $X$, Liu J, Xu M, et al. Remdesivir and chloroquine effectively inhibit the recently emerged novel coronavirus (2019-nCoV) in vitro. Cell Res. 2020 Mar;30(3):269 71. Epub 2020 Feb 4.

3. Goel P, Gerriets V. Chloroquine. Updated 2019 Dec 5. In: StatPearls. Treasure Island (FL):StatPearls Publishing; 2020 Jan [cited 2020 May 14]. Available from: https://www.ncbi.nlm.nih.gov/books/NBK551512/

4. ParkTY, Jang Y,Kim W, Shin J, Toh HT, Kim CH, et al.Chloroquine modulates inflammatory autoimmune responses through Nurr1 in autoimmune diseases. Sci Rep. 2019 Oct 29; 9(1):15559.

5. Yam JCS, Kwok AKH. Ocular toxicity of hydroxychloroquine. Hong Kong Med J. 2006 Aug; 12(4):294-304.

6. Braga CB, Martins AC, Cayotopa AD, Klein WW, Schlosser AR, da Silva $A F$, et al. Side effects of chloroquine and primaquine and symptom reduction in malaria endemic area (Mâncio Lima, Acre, Brazil). Interdiscip Perspect Infect Dis. 2015; 2015: 346853. Epub 2015 Aug 18.

7. Haeusler IL, Chan XHS, Guérin PJ, White NJ. The arrhythmogenic cardiotoxicity of the quinoline and structurally related antimalarial drugs: a systematic review. BMC Med. 2018 Nov 7; 16(1):200.

8. Teixeira RA, Borba EF, Pedrosa A, Nishioka S, Viana VST, Ramires JA, et al. Evidence for cardiac safety and antiarrhythmic potential of chloroquine in systemic lupus erythematosus. EP Europace. 2014 Jun; 16(6):887 92.

9. Jorge A, Ung C, Young LH, Melles RB, Choi HK. Hydroxychloroquine retinopathy - implications of research advances for rheumatology care. Nat Rev Rheumatol. 2018 Dec;14(12):693-703.

10. Joyce $E$, Fabre A, Mahon N. Hydroxychloroquine cardiotoxicity presenting as a rapidly evolving biventricular cardiomyopathy: key diagnostic features and literature review. Eur Heart J Acute Cardiovasc Care. 2013 Mar; 2(1):77-83.

11. Izmirly PM, Costedoat-Chalumeau N, Pisoni CN, Khamashta MA, Kim MY, Saxena A, et al. Maternal use of hydroxychloroquine is associated with a reduced risk of recurrent anti-SSA/Ro-antibody-associated cardiac manifestations of neonatal lupus. Circulation. 2012 Jul 3; 126(1):76-82.

12. Zhou D, Dai SM, Tong Q. COVID-19: a recommendation to examine the effect of hydroxychloroquine in preventing infection and progression.J Antimicrob Chemother. 2020; dkaa114.

13. Principi N,Esposito S.Chloroquine or hydroxychloroquine for prophylaxis of COVID-19. Lancet Infect Dis. 2020 Apr 17;S1473-3099(20)30296-6. 
14. Shah S, Das S, Jain A, Mishra DP, Negi VS. A systematic review of the prophylactic role of chloroquine and hydroxychloroquine in coronavirus disease-19 (COVID-19). Int J Rheum Dis. 2020 May;23(5):61319. Doi:10.1111/1756-185X.13842.

15. Abena PM, Decloedt EH, Bottieau E, Suleman F, Adejumo P, Sam-Agudu $N A$, et al. Chloroquine and hydroxychloroquine for the prevention or treatment of novel coronavirus disease (COVID-19) in Africa: Caution for inappropriate off-label use in healthcare settings. Am J Trop Med Hyg. 2020 Jun; 102(6): 1184-8. doi:10.4269/ajtmh.20-0290.

16. Vastarella $M$, Patrì $A$, Annunziata $M C$, Cantelli $M$, Nappa $P$, Tasso $M$, et al. Can hydroxychloroquine be useful in the prevention of COVID-19? An Italian survey in dermatological and rheumatological patients already under treatment. J Am Acad Dermatol. 2020 Apr 30;501909622(20)30757-X.

17. Gautret $\mathrm{P}$, Lagier JC, Parola $\mathrm{P}$, Hoang VT, Meddeb L, Mailhe $M$, et al. Hydroxychloroquine and azithromycin as a treatment of COVID-19: results of an open-label non-randomized clinical trial. Int J Antimicrob Agents. 2020 Mar 20:105949.

18. Kim AHJ, Sparks JA, Liew JW, Putman MS, Berenbaum F, Duarte-Garcia A et al. A rush to judgment? Rapid reporting and dissemination of results and its consequences regarding the use of hydroxychloroquine for COVID-19. Ann Intern Med. 2020 Mar 30:M20-1223.

19. Geleris J, Sun Y, Platt J, Zucker J, Baldwin M, Hripcsack G, et al Observational study of hydroxychloroquine in hospitalized patients with Covid-19. N Engl J Med. 2020 May 7; NEJMoa2012410.

20. Rosenberg ES, Dufort EM, Udo T, Wilberschied LA, Kumar J, Tesoriero J, et al. Association of treatment with hydroxychloroquine or azithromycin with in-hospital mortality in Patients With COVID-19 in New York State. JAMA. 2020 May 11:e208630. doi:10.1001/jama.2020.8630.

21. Million M, Lagier JC, Gautret $\mathrm{P}$, Colson P, Fourier P-E, Amrane S, et al. Early treatment of COVID-19 patients with hydroxychloroquine and azithromycin: A retrospective analysis of 1061 cases in Marseille, France. Travel Med Infect Dis. 2020 May 5; 101738.

22. World Health Organization. "Solidarity" clinical trial for COVID-19 treatments. Last updated 2020 Jun 4 [cited 2020 Jun 10]. Available from: https://www.who.int/emergencies/diseases/novel-coronavirus-2019/ global-research-on-novel-coronavirus-2019-ncov/solidarity-clinicaltrial-for-covid-19-treatments

23. National Health Commission and State Administration of Traditional Chinese Medicine. Diagnosis and treatment protocol for Novel Coronavirus Pneumonia (Trial Version 6, Revised). 2020 Feb 18 [cited 2020 May 8]. Available from: http://www.kankyokansen.org/uploads/ uploads/files/jsipc/protocol_V6.pdf

24. Indian Council of Medical Research. Advisory on the use of hydroxy-chloroquine as prophylaxis for SARS-CoV-2 infection. New Delhi: ICMR; 2020 Mar 21[cited 2020 May 06]. Available from: https://www.mohfw.gov.in /pdf/Advisoryontheuseof hydroxychloroquineasprophylaxisforSARSCOVID19infection.pdf

25. Ministry of Health and Family Welfare. Revised advisory on the use of Hydroxychloroquine (HCQ) as prophylaxis for COVID-19 infection. New Delhi: MoHFW; 2020 Mar 23[cited 2020 May 6]. Available from: https:// www.mohfw.gov.in/pdf/RevisedadvisoryontheuseofSARSCOVID19 infection.pdf

26. Marchione M."Game changer"? Trump-touted malaria drugs spur hope, shortages. Washington Times. 2020 Mar 23[cited 2020 May 6]. Available from: https://www.washingtontimes.com/news/2020/mar/23/ chloroquine-and-hydroxychloroquine-donald-trump-to

27. US Food and Drug Administration. Letter of Authorisation from Denise F Hinton, Chief Scientist, FDA, to Dr Rick Hinton, Director, BARDA, Dept of Health and Human Services. 2020 Mar 28[cited 2020 May 6]. Available from: https://www.fda.gov/media/136534/download

28. Gao J, Tian Z, Yang X. Breakthrough: Chloroquine phosphate has shown apparent efficacy in treatment of COVID-19 associated pneumonia in clinical studies. Biosci Trends. 2020 Mar 16;14(1):72 3. Epub 2020 Feb 19.

29. Rathi S, Ish P, Kalantri A, Kalantri S. Hydroxychloroquine prophylaxis for COVID-19 contacts in India. Lancet Infect Dis. 2020; S14733099(20):30313-3. Epub 2020 Apr 17.

30. Laday J. FDA's hydroxychloroquine emergency use order for COVID-19 draws mixed reactions. Healio Rheumatology. 2020 Apr 03[cited 2020 May 7]. Available from: https://www.healio.com/rheumatology/ practice-management/news/online/\%7Bb698e9fe-1f57-4ab0-bfe0-
8ca6239d7e8e\%7D/fdas-hydroxychloroquine-emergency-use-orderfor-covid-19-draws-mixed-reactions

31. Pastick KA, Okafor EC, Wang F, Lofgren SM, Skipper CP, Nicol MR, et al. Review: Hydroxychloroquine and Chloroquine for Treatment of SARSCoV-2 (COVID-19). Open Forum Infect Dis. 2020 Apr 15;7(4):ofaa130. eCollection 2020 Apr.

32. Sarayani A, Cicali B, Henriksen CH, Brown JD. Safety signals for QT prolongation or Torsades de Pointes associated with azithromycin with or without chloroquine or hydroxychloroquine. Res Social Adm Pharm. 2020 Apr 19; S1551-7411(20)30391-0.

33. Yazdany J, Kim AHJ. Use of hydroxychloroquine and chloroquine during the COVID-19 pandemic: What every clinician should know. Ann Intern Med. 2020 Jun 2; M20-1334. Epub 2020 Mar 31.

34. Ferner RE, Aronson JK. Hydroxychloroquine for COVID-19: What do the clinical trials tell us? 2020 Apr 14[cited 2020 May 7]. Available from: https://www.cebm.net/covid-19/hydroxychloroquine-for-covid-19what-do-the-clinical-trials-tell-us/

35. Expert consensus on chloroquine phosphate for the treatment of novel coronavirus pneumonia. Zhonghua Jie He He Hu Xi Za Zhi [Chinese Journal of Tuberculosis and Respiratory Diseases]. 2020 Mar 12;43(3):185-8. [Chinese]. Doi:10.3760/cma.j.issn.1001-0939.2020.0019.

36. US Food and Drug Administration. Fact sheet for health care providers. Emergency use authorization (EUA) of hydroxychloroquine sulfate supplied from the strategic national stockpile for treatment of COVID-19 in certain hospitalized patients. 2020 Apr 27 [cited 2020 May 6]. Available from: https://www.fda.gov/media/136537/download

37. Warren TK, Jordan R, Lo MK, Ray AS, Mackman RL, Soloveva V, et al. Therapeutic efficacy of the small molecule GS-5734 against Ebola virus in rhesus monkeys. Nature. 2016 Mar 17;531:381-5.

38. Mulangu S, Dodd LE, Davey RT Jr, Mbaya OT, Proschan M, Mukadi D, et al. A Randomized, Controlled Trial of Ebola Virus Disease Therapeutics. $N$ Engl J Med. 2019 Dec 12;381(24):2293-303.

39. Scavone C, Brusco S, Bertini M, Sportiello L, Rafaniello C, Zoccoli A, et al. Current pharmacological treatments for COVID-19: What's next? $\mathrm{Br} J$ Pharmacol. 2020 May 15;10.1111/bph.15072. Epub ahead of print.

40. Sheahan TP, Sims AC, Graham RL, Menachery VD, Gralinski LE, Case JB, et al. Broad-spectrum antiviral GS-5734 inhibits both epidemic and zoonotic coronaviruses. Sci Transl Med. 2017 Jun 28;9(396):eaal3653.

41. Sheahan TP, Sims AC, Leist SR, Schafer A, Won J, Brown AJ, et al. Comparative therapeutic efficacy of remdesivir and combination lopinavir, ritonavir, and interferon beta against MERS-CoV. Nat Commun. 2020 Jan 10;11(1):222.

42. de Wit E, Feldmann F, Cronin J, Jordan R, Okumura A, Thomas T, et al. Prophylactic and therapeutic remdesivir (GS-5734) treatment in the rhesus macaque model of MERS-CoV infection. Proc Natl Acad Sci USA. 2020 Mar 24;117(12):6771-6776.

43. National Institutes of Health. Potential antiviral drugs under evaluation for the treatment of COVID-19. Updated 2020 May 12 May [cited 2020 May 14]. Available from: https://www.covid19treatmentguidelines.nih. gov/antiviral-therapy/

44. Grein J, Ohmagari N, Shin D, Diaz G, Asperges E, Castagna A, et al. Compassionate Use of Remdesivir for Patients with Severe Covid-19. N Engl J Med.2020 Jun 11;NEJMoa2007016. Epub 2020 Apr 10.

45. Wang Y, Zhang D, Du G, Du R, Zhou J, Jin Y, et al. Remdesivir in adults with severe COVID-19: a randomised, double-blind, placebo-controlled, multicentre trial. Lancet 2020 May 16;395(10236):1569-78. Epub 2020 Apr 29.

46. Mahase E. Covid-19: Remdesivir is helpful but not a wonder drug, say researchers. BMJ. 2020 May 1;369:m1798.

47. US Food and Drug Administration. Letter of Emergency Use Authorization (EUA) for emergency use of remdesivir for the treatment of hospitalized 2019 coronavirus disease (COVID-19) patients, to Gilead Sciences, Inc. 2020 May 1 [cited 2020 May 6]. Available from: https:// www.fda.gov/media/137564/download

48. National Institutes of Health. Covid-19 treatment guidelines: Remdesivir. Updated 2020 May 12 [cited 2020 May 14]. Available from: https://www. covid19treatmentguidelines.nih.gov/antiviral-therapy/remdesivir/

49. Rowland C. Government researchers changed metric to measure coronavirus drug remdesivir during clinical trial. Msn.com. 2020 May 1[cited 2020 May 13]. Available from: https://www.msn.com/en-us/ news/us/government-researchers-changed-metric-to-measure- 
coronavirus-drug-remdesivir-during-clinical-trial/ar-BB13ui2k

50. Canadian Agency for Drugs and Technologies in Health. Remdesivir Updated 2020 Apr 20 [cited 2020 May 23]. Available from: https://covid. cadth.ca/treatment/remdesivir/

51. Rajagopal D. WHO calls halt to solidarity trial of HCQ. Economic Times. 2020 May 26 [cited 2020 Jun 2]. Available from: https://economictimes. indiatimes.com/industry/healthcare/biotech/pharmaceuticals/ who-calls-halt-to-solidarity-trial-of-hcq/articleshow/75990966. cms?from $=\mathrm{mdr}$

52. Chitguppi R. Lancet faces severe criticism from scientific community Hydroxychloroquine study is hiding data. Dental Tribune, South Asia edition. 2020 May 30 [cited 2020 Jun 2]. Available from:https://in.dentaltribune.com/news/lancet-faces-severe-criticism-from-scientificcommunity-hydroxychloroquine-study-is-hiding-data/

53. Mehra MR, Ruschitzka F, Patel AN. Retraction - Hydroxychloroquine or chloroquine with or without a macrolide for treatment of COVID-19: a multinational registry analysis [retraction of: Lancet. 2020 May 22;]. Lancet. 2020 Jun 5[cited 2020 Jun 10]; S0140-6736(20)31324-6. doi:10.1016/S0140-6736(20)31324-6. Online ahead of print.

54. ANI.ICMR writes to WHO, says international HCQ trial dosages four times higher than Indian trials. 2020 May 29 [cited 2020 Jun 2]. Available from: https://www.timesnownews.com/health/article/icmr-writes-to-whosays-international-hcq-trial-dosages-four-times-higher-than-indiantrials/598726

55. Randomised Evaluation of COVID-19 Therapy (RECOVERY). Recruitment to the RECOVERY Trial continues as planned. 2020 May 26 [cited 2020 Jun 2]. Available from: https://www.recoverytrial.net/news/recruitmentto-the-recovery-trial-continues-as-planned
56. Mishra M, Maddipatla M.Reuters. Gilead ties up with generic drugmakers for COVID-19 drug supply. Reuters. 2020 May 12 [cited 2020 Jun 2]. Available from: https://in.reuters.com/article/us-health-coronavirusgilead-sciences/gilead-ties-up-with-generic-drugmakers-for-covid-19drug-supply-idINKBN22O2HJ

57. Beigel JH, Tomashek KM, Dodd LE, Mehta AK, Zingman BS, Kalil AC, et al. Remdesivir for the treatment of Covid-19 - Preliminary report. $N$ Engl J Med. 2020 May 22;10.1056/NEJMoa2007764. Epub ahead of print.

58. Business Wire. Gilead announces results from phase 3 trial of Remdesivir in patients with moderate COVID-19. Businesswire.com. 2020 Jun 1[cited 2020 Jun 2]. Available from: https://www.businesswire.com/ news/home/20200601005310/en/

59. Institute for Clinical and Economic Review. Alternative pricing models for Remdesivir as a Treatment for COVID-19.2020 May1 [cited 2020 May 7]. Available from: https://icer-review.org/announcements/alternative pricing_models_for_remdesivir/

60. Borba MGS, Val FFA, Sampaio VS, Alexandre MAA, Melo GC, Brito M, et al. Effect of high vs low doses of chloroquine diphosphate as adjunctive therapy for patients hospitalized with Severe Acute Respiratory Syndrome Coronavirus 2 (SARS-CoV-2) infection: a randomized clinical trial. JAMA Netw Open. 2020 Apr 1;3(4):e208857.

61. US Food and Drug Administration. FDA cautions against use of hydroxychloroquine or chloroquine for COVID-19 outside of the hospital setting or a clinical trial due to risk of heart rhythm problems. 2020 Apr 24[cited May 7]. Available from: https://www.fda.gov/drugs/drugsafety-and-availability/fda-cautions-against-use-hydroxychloroquineor-chloroquine-covid-19-outside-hospital-setting-or

\section{Covid-19 chemoprophylaxis: Ethics of prevention based on anecdotal evidence}

SUNIL KUMAR PANIGRAHI, SAGARIKA MAJUMDAR, ANJALI PAL, PRAGYAN PARAMITA PARIJA, BHARAT DU

\section{Abstract}

The ongoing pandemic of Covid-19 caused by the SARS-CoV-2 virus has infected more than 6 million all over the world and has caused more than 3.8 lakh fatalities till date. Health workers are the frontline responders and are exposed to a plethora of health hazards. Recently, an advisory by the Indian Council of Medical Research for the use of hydroxychloroquine as postexposure prophylaxis was hailed as an outstanding initiative for the protection of healthcare workers and high risk contacts of

Authors: Sunil Kumar Panigrahi (sunil1986panigrahi@gmail.com), Senior Resident, Department of Community and Family Medicine, AlIMS, Raipur INDIA; Sagarika Majumdar (sagarikamajumdar84@gmail.com), Senior Resident, Department of Obstetrics and Gynaecology, AlIMS, Raipur INDIA Anjali Pal (anjalipal@aiimsraipur.edu.in), Associate Professor, Department of Community and Family Medicine, AIIMS, Raipur, INDIA; Pragyan Paramita Parija (pragyanparija@gmail.com),Senior Resident, Centre for Community Medicine, AlIMS, New Delhi, INDIA; Bharath DU (barathdu@gmail.com), Consultant Psychiatrist, District Mental Health Programme, Chamarajanagar, Karnataka INDIA.

To cite: Panigrahi S, Majumdar S, Pal A, Parija PP, Bharath DU. Covid-19 chemoprophylaxis: Ethics of prevention based on anecdotal evidence. Indian J Med Ethics. 2020 Jul-Sep; 5(3) NS: 207-12. DOI: 10.20529/IJME.2020.066.

Published online on June 8, 2020.

Peer Reviewers: An anonymous reviewer

(c) Indian Journal of Medical Ethics 2020 patients. But the evidence of effectiveness available is only from in vitro studies and non-randomised control trials of insufficient sample size. Several ongoing large scale clinical trials are focused on the same research questions, the preliminary results of which are still awaited. The present study discusses the ethics of the introduction of therapeutic or preventive interventions based on limited available evidence during the ongoing pandemic of Covid-19.

Keywords: Covid-19, chemoprophylaxis, hydroxychloroquine, cardiovascular disease, co-morbidities, ICMR

\section{Introduction}

The ongoing pandemic of Covid-19 caused by the SARS-CoV-2 virus has infected more than 6 million all over the world, and has caused more than 3.8 lakh fatalities till date (1). Health workers, including doctors, nurses, laboratory personnel and other support staff are the frontline responders and face hazards such as pathogen exposure, long working hours, psychological distress, fatigue, occupational burnout, stigma and physical and psychological violence (2). Initial data from Wuhan in China, the earliest hotspot, indicates that the risk of infection among health workers is thrice that among the general population. Infection prevention and control (IPC) and appropriate personal protective equipment (PPE) has been proven to be effective in prevention of infection among 